\title{
Evidencia sobre el efecto anticariogénico de pastas dentales que contienen arginina: una revisión sistemática.
}

\author{
Gisela Nataly Rubín De Celis-Quintana ${ }^{1}$, Adriana Moreno-Rodrígues², \\ Rafael Torres-Rosas ${ }^{3,4}$ y Liliana Argueta-Figueroa ${ }^{5}$ \\ ${ }^{1}$ Doctorado en Ciencias Odontológicas y de la Salud, División de Posgrado, Facultad \\ de Odontología, Universidad Autónoma Benito Juárez de Oaxaca. Oaxaca, México. \\ ${ }^{2}$ Facultad de Ciencias Químicas, Universidad Autónoma Benito Juárez de Oaxaca. \\ Oaxaca, México. \\ ${ }^{3}$ División de Posgrado, Facultad de Odontología, Universidad Autónoma Benito Juárez \\ de Oaxaca. Oaxaca, México. \\ ${ }^{4}$ Laboratorio de Inmunología asociado al Centro de Estudios en Ciencias de la Salud \\ y la Enfermedad, Facultad de Odontología, Universidad Autónoma Benito Juárez \\ de Oaxaca. Oaxaca, México. \\ ${ }^{5}$ Cátedras-Conacyt - Facultad de Odontología, Universidad Autónoma Benito Juárez \\ de Oaxaca. Oaxaca, México.
}

Palabras clave: arǵinina; fluoruro; dentífrico; prevención; caries dentales.

Resumen. Las bacterias arǵinolíticas metabolizan la arginina que se encuentra en la saliva produciendo amoníaco, el cual potencialmente es un factor endógeno de inhibición de la microbiota cariogénica. Las pastas dentales con arginina podrían brindar mayor disponibilidad de dicho compuesto y, por tanto, ayudar a la prevención de caries. El propósito de esta revisión fue evaluar la evidencia publicada acerca del efecto anticariogénico de pastas dentales que contienen arǵinina. Se realizó una revisión sistemática de literatura, en las bases de datos PubMed, Scholar Google y Web of Science, publicada en el período 2010 a 2020. Los criterios de eleǵibilidad fueron artículos oriǵinales con diseño de ensayos clínicos aleatorizados y observacionales, en texto completo en inglés o español, con participantes de todas las edades, en los cuales se hubiera evaluado el efecto anticariogénico de la arginina. De los 424 registros identificados, se revisaron 42 artículos en texto completo. De éstos, siete estudios se seleccionaron por cumplir los criterios de elegibilidad. En tres estudios se observó una disminución en el incremento de procesos cariosos, dos estudios determinaron que la actividad del sistema arǵinina deiminasa es mayor, la remineralización 
de lesiones incipientes en esmalte lo reportan dos estudios, así como la reducción en la producción de ácido láctico. No se reportaron efectos secundarios relacionados con la arginina. Con base en el análisis de los estudios incluidos, se concluye que los dentífricos que contienen una combinación de fluoruro y arginina, poseen una mayor cantidad de beneficios y actividad anticariogénica cuando se comparan con dentífricos convencionales.

\title{
Evidence on the anticariogenic effect of arginine-containing toothpastes: a systematic review.
}

Invest Clin 2021; 62 (2): 169-188

Key words: arginine; fluoride; toothpastes; prevention; dental caries.

\begin{abstract}
Arginolytic bacteria metabolize the arginine found in saliva, producing ammonia, which is, potentially, an inhibitory endogenous factor of the cariogenic microbiota. Arginine-containing toothpastes could provide greater availability of this amino acid and therefore help to prevent cavities. The aim of this study was to evaluate the published evidence about the anti-cariogenic effect of arginine-containing toothpastes. A systematic literature review was carried out in the PubMed, Scholar Google, and Web of Science databases published in the period from 2010 to 2020 . The eligibility criteria were original articles with the design of randomized and observational clinical trials, published in full-text in English or Spanish, with participants of all ages, in which the anti-cariogenic effect of arginine was evaluated. Of the 424 records identified, 42 full-text studies were reviewed. Seven studies were selected for meeting the eligibility criteria. In three of the studies there was a decrease in the development of caries; two studies determined that the activity of the arginine deiminase system is greater. The remineralization of incipient lesions in the enamel is reported by two studies, as well as the reduction in the production of lactic acid. No arginine-related side effects were reported. According to the analysis of the included studies, it can be concluded that toothpastes containing a combination of fluoride and arginine, possess a greater amount of benefits and anticariogenic activity when compared to conventional toothpastes.
\end{abstract}

Recibido: 18-01-2021 Aceptado: 20-03-2021

\section{INTRODUCCIÓN}

La caries es una enfermedad infecciosa con diversos factores de riesgo (1); a pesar de ello, la población infantil es la más susceptible $(2,3)$. En la etapa inicial de formación de la biopelícula, los Streptococcus mutans son una especie de bacterias que, como resultado del metabolismo de los carbohidratos ingeridos en la dieta, sintetizan productos intra y extracelulares, los cuales disminuyen el pH oral $(4,5)$. Una disminución repetitiva del $\mathrm{pH}$ oral puede causar la disolución de los cristales de hidroxiapatita en el esmalte, 
oriǵinando la desmineralización del diente y, en consecuencia, la posibilidad de generar caries $(3,6)$.

Para controlar la formación de la biopelícula se ha propuesto la generación de diversos bioactivos con propiedades antibacterianas. Entre los candidatos destacan el desarrollo de nanopartículas para su uso en cavidad oral con baja citotoxicidad y alta actividad antibacteriana $(7,8)$; particularmente han recibido gran atención las nanopartículas de metales como el oro, plata y cobre por este efecto $(9,10)$. Por otro lado, el quitosano también ha sido estudiado porque exhibe propiedades antibacteriales $\mathrm{y}$ alta biocompatibilidad (11). Sin embargo, hasta el momento, estos otros compuestos no se encuentran disponibles para la prevención de caries de forma comercial como pasta dental.

Por otra parte, se ha reportado en la literatura que uno de los mecanismos homeostáticos de la cavidad oral para mantener el $\mathrm{pH}$ neutro es mediante la actividad de las bacterias arginolíticas $(2,12)$, las cuales producen amoníaco a través del Sistema Arginina Deiminasa (SAD). Dichas bacterias arǵinolíticas metabolizan a la arginina (la cual se encuentra en forma libre y es parte de la composición de la saliva) produciendo energía y trifosfato de adenosina, carbono y amoniaco $(13,14)$. Este mecanismo de control ha generado líneas de investigación de otros plausibles tratamientos menos agresivos con la biopelícula oral. Estudios in vitro han postulado que dicho amoníaco puede ser un factor endógeno inhibitorio de la microbiota cariogénica, permitiendo la estabilización de la microbiota oral (15). Con esto, se disminuiría la desmineralización del esmalte dental neutralizando la acidez del medio lo que promovería la mineralización y, por tanto, la prevención de caries $(2,16,17)$.

Desde hace muchos años, el uso de fluoruro como medio preventivo en el control de caries ha dado resultados positivos. Sin embargó, al entender el proceso de caries, han surgido opciones enfocadas a controlar el modo de acción de la biopelícula (16). De esta manera, se ha propuesto que el empleo de las pastas dentales con arǵinina, podría brindar mayor disponibilidad salival de dicho compuesto para ser metabolizada en forma de amoníaco. En este sentido, la arginina sólo logra mantener un equilibrio dentro del ambiente de la microbiota oral, reduciendo la actividad de las bacterias acidógenas-acidúricas, mas no es un agente antimicrobiano (3). Asimismo, se ha estudiado -in vitro- el efecto de las pastas dentales con un contenido de $1,5 \%$ de arginina y $1.450 \mathrm{ppm}$ de fluoruro en una base de calcio, encontrándose que estas tienen mayores ventajas en comparación con aquellas que únicamente contienen fluoruro (17).

El propósito de esta revisión de la literatura es determinar la evidencia del efecto anticariogénico de las pastas dentales que contienen argininina para prevenir el desarrollo de caries y la progresión de las lesiones de caries existentes tanto en niños como en adultos.

\section{MATERIAL Y MÉTODOS}

\section{Protocolo y registro}

No se registró el protocolo de esta revisión sistemática.

\section{Criterios de elegibilidad}

En esta revisión se incluyeron artículos originales con diseño de ensayos clínicos aleatorizados controlados y estudios analíticos observacionales en los que el objetivo de investigación fue determinar el efecto anticariogénico de la arǵinina. Estos estudios deben incluir, al menos, un grupo de intervención al cual se le administren dentífricos con fluoruro más argínina y, un grupo control, al cual se le administraron dentífricos sin arǵinina. Las definiciones PICO (participantes, intervención, comparador y desenlace) se encuentran en la Tabla I.

En la búsqueda, se aplicó restricción de idioma a aquellos textos completos de es- 
TABLA I

ESTRATEGIA DE BÚSQUEDA PARA LA SELECGIÓN DE LOS ESTUDIOS.

Población

Intervención

Comparador

Desenlaces

(Outcome)

Diseño de estudio

Idioma

Bases electrónicas

Pregunta de

Investiǵación

Algoritmos

Pubmed: 20

Scholar Gooǵle: 396

Web of Science: 8
1.- Niños y adultos aparentemente sanos, con o sin caries al inicio del estudio.

2.- Pasta dental con Arǵinina

3.- Pasta dental con Fluoruro

4.- CPOD/CPOS (Cariado, Perdido, Obturado por Diente o Superficie)

5.- SAD (Sistema Arǵinina Deiminasa)

6.- Desmineralización (Área y grado)

7.- Ensayos clínicos aleatorizados controlados y observacionales analíticos, con al menos diez participantes por estudio.

Inǵlés y español.

Medline/PubMed, Scholar Google y Web of Science

¿Cuál es la evidencia del uso de pastas dentales con fluoruro-arǵinina en comparación con las pastas dentales sin argininina para la prevención de la caries dental?

Fueron adaptados para cada base de datos

((((arginine) AND (fluoride)) AND (toothpaste)) AND (dental caries)) AND ((prevention OR preventive)) Último acceso: 04/05/2020

"dental caries prevention" AND argininine AND fluoride AND (toothpaste or dentifrices)

Specific interval: 2010-2020

"prevención de caries" y arginina y fluoruro y (pastas de dientes o dentífricos) Intervalo específico: 2010-2020

Último acceso: 07/05/2020

\#1 TS="dental caries prevention"

$\# 2$ TS=arginine

\#3 TS=fluoride

\#4 TS= toothpaste

\#5 TS=dentifrices

\#6 (\#3 AND \#2 AND \#1)

$\# 7$ (\#5 or \#4)

\#8 (\#7 AND \#6)

AND TYPES OF DOCUMENTS: (Article) Indices=SCI-EXPANDED, SSCI, A\&HCI, CPCI-S, CPCI-SSH, BKCI-S, BKCI-SSH, ESCI Specific interval $=2010-2020$

\#1 TS="prevención de caries “

\#2 TS=arginina

\#3 TS=fluoruro

$\# 4 \mathrm{TS}=$ pasta de dientes

\#5 TS=dentífrico

\#6 (\#3 y \#2 y \#1)

\#7 (\#5 о \#4)

\#8 (\#7 y \#6)

Y TIPOS DE DOCUMENTOS: (Artículo) Índices=SCI-EXPANDED, SSCI, A\&HCI, CPCI-S, CPCI-SSH, BKCI-S, BKCI-SSH, ESCI Periodo de tiempo $=2010-2020$ 
tudios en idioma inǵlés y español y con restricción de tiempo de publicación, incluyendo solo a la literatura publicada entre 2010 y 2020 .

\section{Fuentes de Información y búsqueda}

Dos autores (GNRCQ y RTR) diseñaron los algoritmos de búsqueda de literatura basados en la estrategía PICO, seleccionando palabras a partir de la terminología MeSH (Medical Subject Headingss) (18). La búsqueda se realizó en las bases de datos Pubmed, Google Scholar y Web of Science, durante los meses de enero a abril de 2020 con último acceso de actualización en mayo del 2020, la estrategia de búsqueda se ha resumido en la Tabla I.

\section{Selección de los estudios}

Dos autores (GNRCQ y AMR) llevaron a cabo el proceso de selección de los estudios siguiendo los lineamientos Preferred Reporting Items for Systematic reviews and Meta-Analyses (PRISMA) (19, 20). El tamizaje de los registros que cumplieron con los criterios de selección fue a través de la evaluación de los títulos y resúmenes de los artículos que respondían a la pregunta de investigación y que estuvieran publicados en revistas con revisión por pares, ya sean arbitradas o indexadas, con el propósito de que éstos contaran con una calidad mínima.

\section{Evaluación de riesgo de sesgo}

Para la evaluación del riesgo de sesgo de los estudios incluidos se siguieron las recomendaciones del capítulo 8 de Cochrane Handbook for Systematic Reviews of Interventions (21) y se utilizó la herramienta RoB 2 (Risk of Bias 2) (22). Se encargaron de este proceso 2 revisores de forma independiente (GNRCQ y RTR) y en caso de existir discrepancias, se resolvieron mediante un tercer revisor (LAF).
Proceso de recolección de datos, ítems de los datos, medidas de resumen y síntesis de resultados

Toda la información de los artículos fue registrada por dos autores (GNRCQ y LAF) de forma independiente, en una base de datos donde los siguientes ítems fueron recabados: tipo de estudio, número de participantes, edad promedio, participantes y características del grupo de intervención y grupo control, instrumentos de medición, unidad de medida, resultados por grupo, análisis estadístico realizado en cada estudio y valor de $p$ reportado. Como medidas de desenlace primario se consideraron la efectividad (ya sean medidas directas o indirectas de ésta) de la pasta de fluoruro-arginina para la prevención de earies (CPOD/CPOS, la actividad del Sistema Arginina Deiminasa (SAD), el área y grado de desmineralización y pH de la placa, el perfil metabólico de la biopelícula y la producción de ácido láctico; y como desenlace secundario, fueron los efectos adversos de la intervención. La síntesis cualitativa de resultados se llevó a cabo.

\section{RESULTADOS}

\section{Selección de los estudios}

El proceso de identificación, selección y tamizaje se muestra a detalle en la Fig. 1. Después del tamizaje, 7 artículos (Kraivaphan y col. 2013, Yin y col. 2013, Srisilapan y col. 2013, Nascimento y col. 2014, Li y col. 2015, Xue y col. 2017, Nascimento y col. 2019) cumplieron los criterios de elegibilidad para ser incluidos en esta revisión sistemática.

\section{Características de los estudios}

En 4 estudios analizados, los participantes fueron niños y adolescentes $(17,23$, $24,26)$ y, en 3 de ellos, los participantes fueron adultos $(3,25,27)$. Los niños y adolescentes participantes pertenecían a escuelas primarias y secundarias. Los adultos participantes fueron invitados en clínicas dentales 


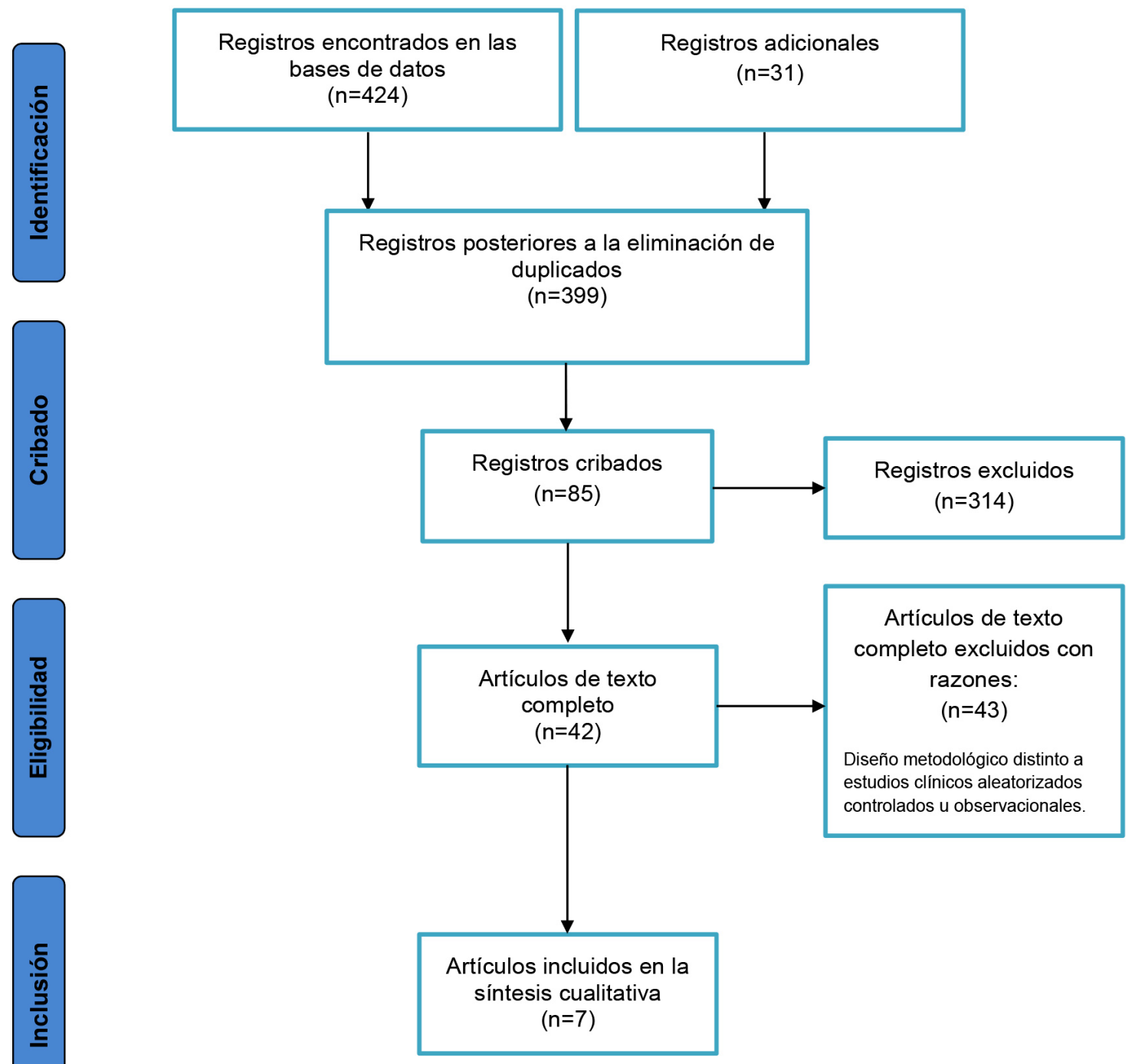

Fig. 1. Diagrama de flujo PRISMA de la revisión sistemática.

universitarias $\mathrm{u}$ hospitales. Los participantes de los estudios podían o no presentar lesiones cariosas al inicio del estudio, pero no debían presentar aparatos de ortodoncia o utilizar prótesis orales.

Todos los estudios utilizaron como intervención dentífricos con arginina al 1,5\% en bases de fosfato dicálcico, fluoruro de sodio (NaF), monofluorofosfato de sodio (MFP) o incluso sin flúor. Sólo un estudio utilizó dentífrico con arginina al 8\% y 1.450 ppm de $\mathrm{NaF}$ (3). Los grupos control incluyeron den- tífricos con NaF que variaban entre 1.100 y $1.450 \mathrm{ppm}$. A los participantes se les indicó un cepillado de dos veces al día.

Con respecto al diseño de estudio, 6 estudios fueron clínicos aleatorizados, controlados y doble cieǵo $(3,16,23,24,26,27)$ y, 1 fue un estudio clínico aleatorizado, simple y ciego (25). Los participantes de todos los estudios reportaron estar sistémicamente sanos, sin historial de reacciones adversas a la arginina, sin antecedentes de uso de antibióticos previo al período de estudio. El 
número total de participantes fue de 11.617 participantes, de los cuales 11.493 tenían una edad entre 6 y 14 años $(16,23,24,26)$ y 124 tenían entre 18 y 65 años de edad $(3,25,27)$. En todos los estudios incluidos, independientemente del grupo etario de los participantes, se observaron exclusivamente dientes permanentes. En dos estudios se evaluaron los dientes anteriores superiores $(23,24)$, en otro estudio se consideraron las superficies lisas de todos los dientes permanentes (25) y en el resto de los estudios incluidos, se valoraron todos los dientes permanentes, sin especificar cuáles superficies dentales $(3,16,26,27)$. Sólo en tres artículos $(3,25,27)$ reportaron una población de 72 sujetos con diaǵnóstico de caries activa y 68 sujetos libres de caries; el resto de los estudios no específica la relación entre los participantes con caries activa-libre de caries. De los resultados de los estudios incluidos, se obtuvieron los siguientes desenlaces: el índice CPOD/CPOS $(16,26,27)$, la producción de amoníaco a partir del SAD $(25,27)$, inactividad de lesión cariosa (27), medición del área y grado de desmineralización $(23,24)$, sí como la medición de producción de ácido láctico - actividad metabólica y cambios en la biomasa de placa (3).

El tiempo de seguimiento de los participantes en los estudios variaron entre 4 semanas (25) y 24 meses $(16,26)$, de los cuales dos estudios coincidieron en tiempo de 6 meses $(23,24)$ y emplearon, para el diaǵnóstico y evaluación de la intervención, la técnica de fluorescencia cuantitativa inducida por la luz QLF (Inspektor Research Systems BV) para calcular el área de la lesión y pérdida de fluorescencia $(23,24)$. El resumen de los resultados puede observarse en la Tabla II.

\section{Riesgo de sesgo}

La determinación del riesgó de sesgo de los estudios puede verse en la Fig. 2. Cinco estudios tuvieron riesgo de sesgo moderado (debido a la ausencia de registro de protocolo del estudio clínico y la potencial selección de los resultados reportados), un estudio presentó sesǵo alto (debido a selección de los resultados reportados y fallas en la aleatorización) y uno mostró riesǵo de sesgo bajo ( pequeña). Por otra parte, debe considerarse que, en esta revisión, 6 estudios fueron patrocinados por Colgate-Palmolive parcial o totalmente; únicamente hubo un estudio sin patrocinio del fabricante (3). Además, algunos investigadores de ciertos estudios $(16,24,26)$ son trabajadores de la compañía Colgate-Palmolive.

\section{Resultados de los estudios individuales Reducción de CPOD/CPOS}

De los 7 estudios incluidos, dos de ellos $(16,26)$ evaluaron la eficacia en la reducción del CPOD/CPOS con dos pastas dentífricas, una con $1,5 \%$ de arǵinina con fosfato dicálcico o carbonato de calcio y 1.450 ppm de fluoruro, comparado con un dentífrico de control con $1.450 \mathrm{ppm}$ de fluoruro. Los resultados mostraron que, después de dos años de uso de los dos dentífricos con arginina, estos proporcionaron reducciones en las puntuaciones incrementales de un 21\% para CPOD y $19,6 \%$ para CPOS en comparación con el dentífrico control, proporcionando niveles similares de eficacia y controlando la cavitación de lesiones de caries en poblaciones de bajo a moderado riesgo de caries. Con respecto a la disminución de incrementos en procesos cariosos (27), se evaluó la inactividad de lesiones después de 12 semanas de tratamiento. Se encontró que el 14\% de las lesiones eran inactivas, posterior al uso de dentífricos con arginina al 1,5\%. Esta inactividad fue observada más en lesiones en esmalte que en lesiones en dentina.

\section{Actividad del Sistema Arģinina Deiminasa (SAD)}

Dos estudios $(25,27)$ determinaron que el uso de un dentífrico con arginina al $1,5 \%$ incrementa la actividad del $\mathrm{SAD}$, mejorando la capacidad de los microorganismos presentes en placa para producir amoníaco a partir de los sustratos naturales de la sali- 

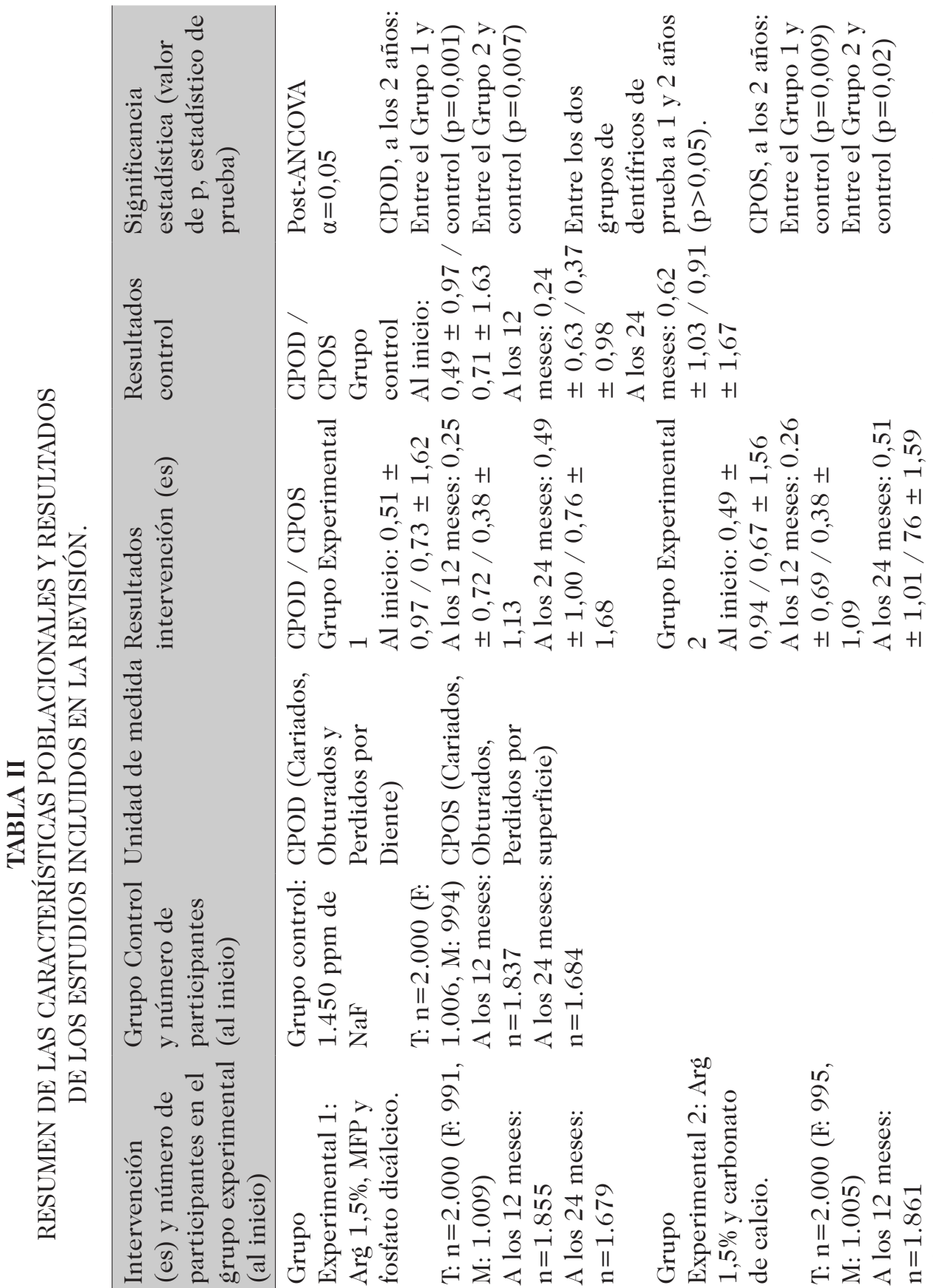

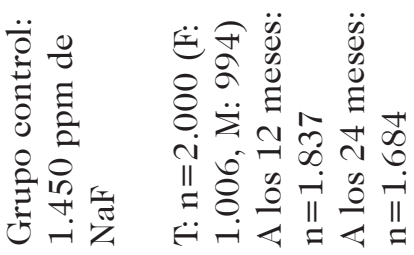
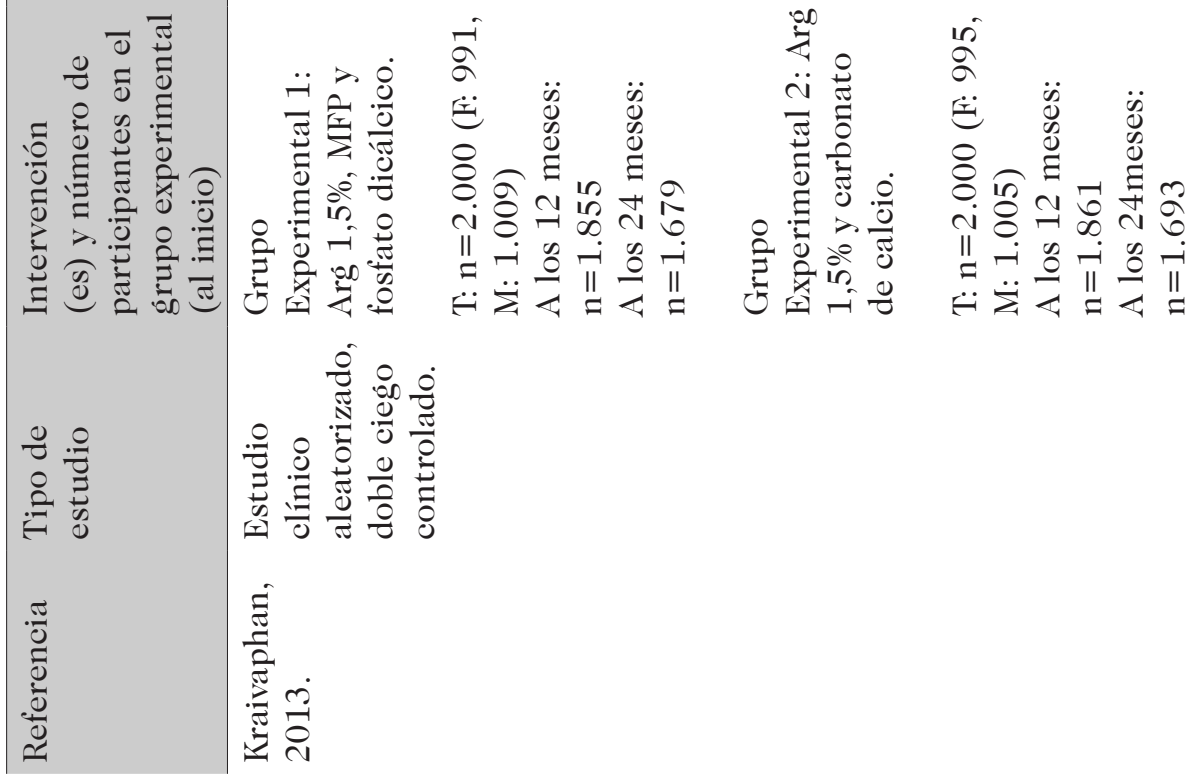


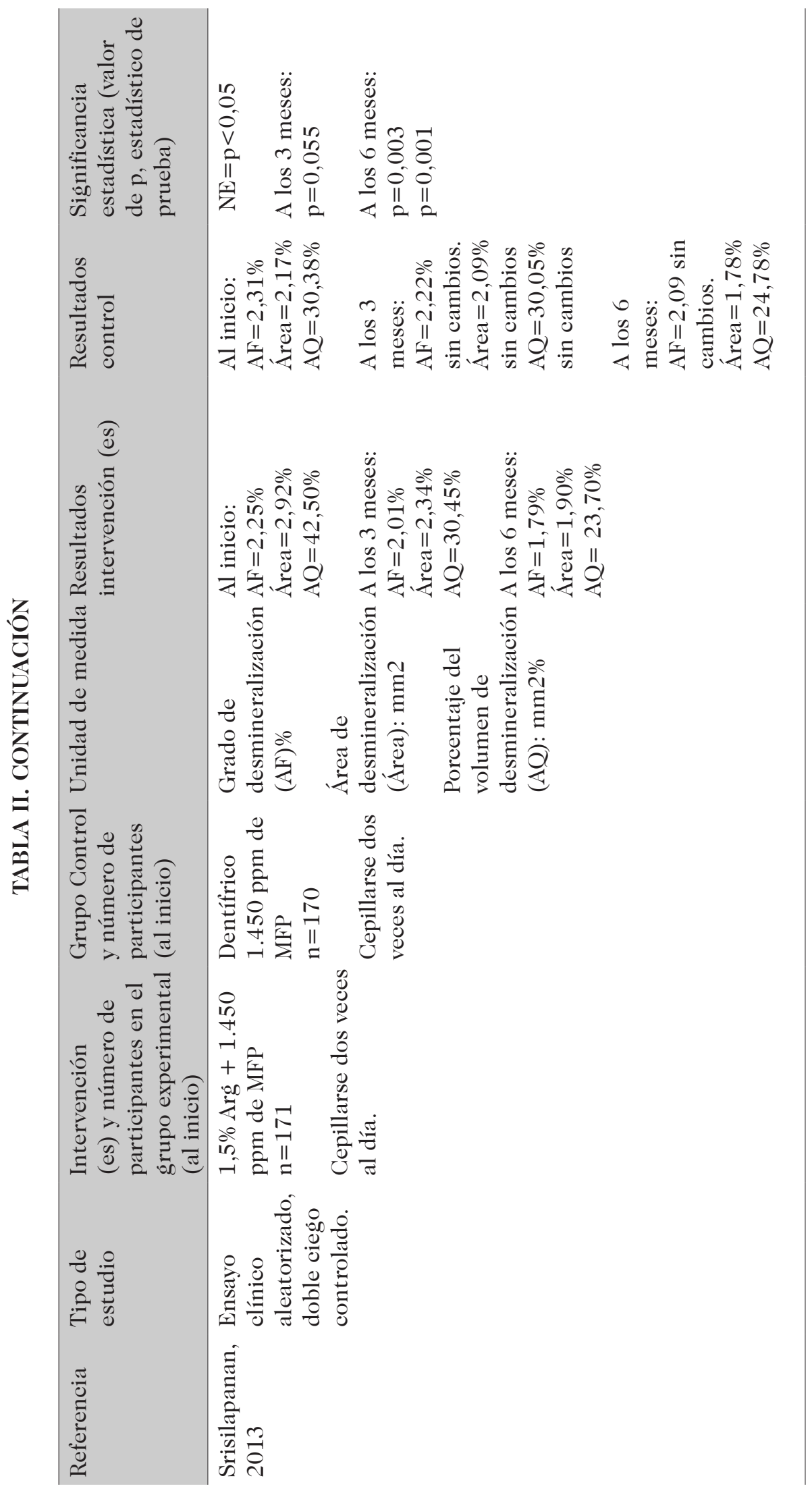

Vol. 62(2): 169 - 188, 2021 


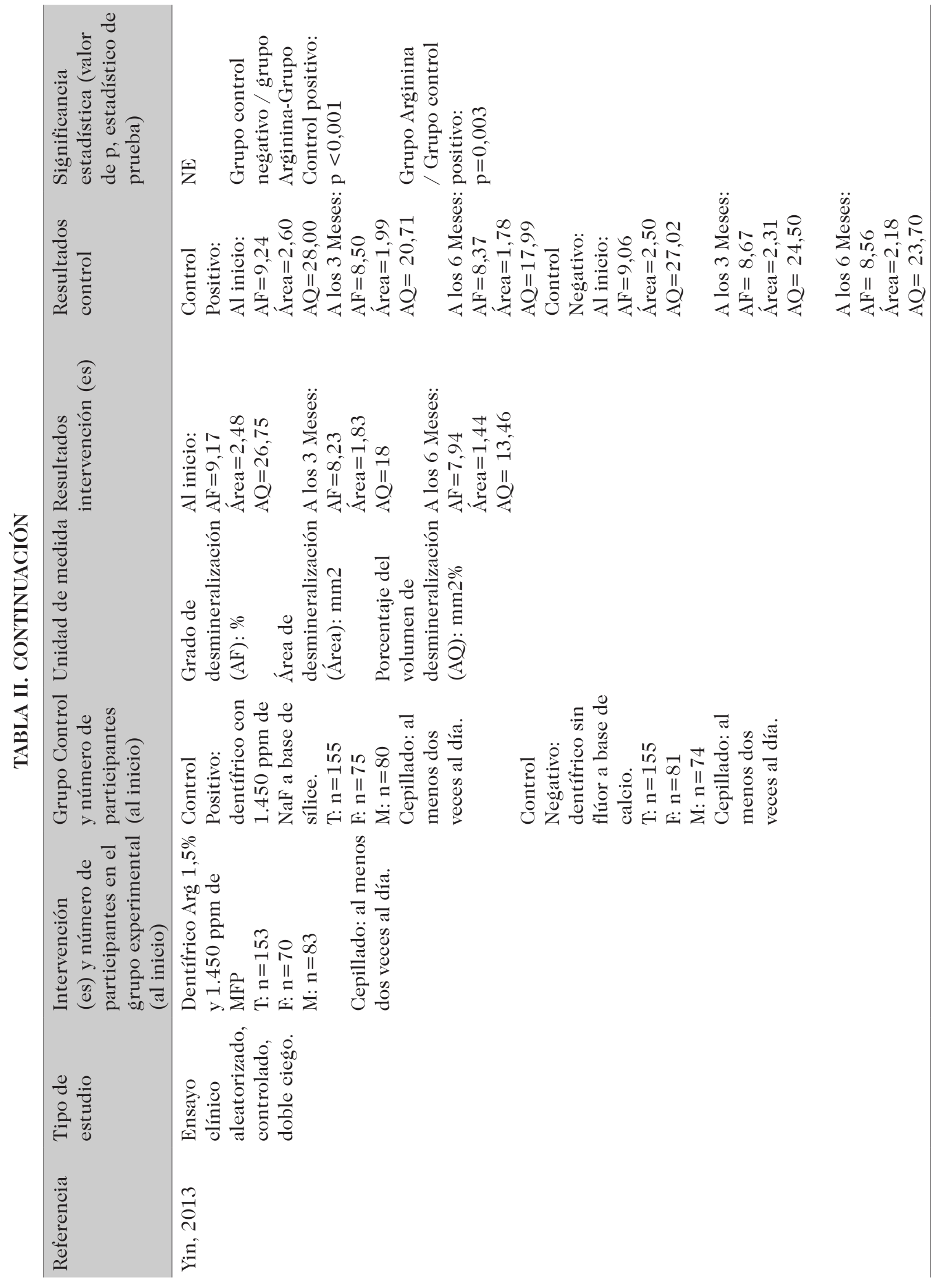




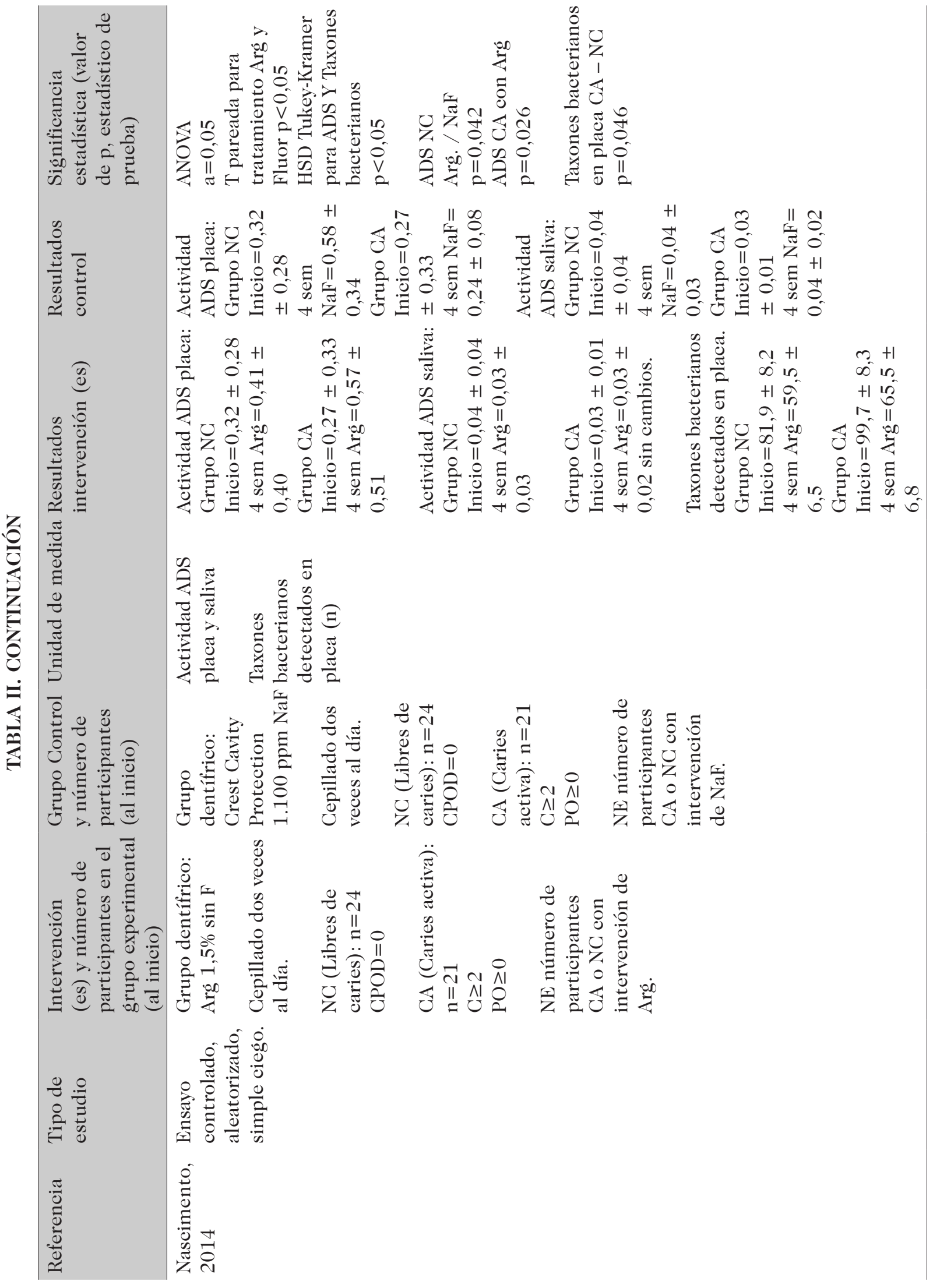

Vol. 62(2): 169 - 188, 2021 

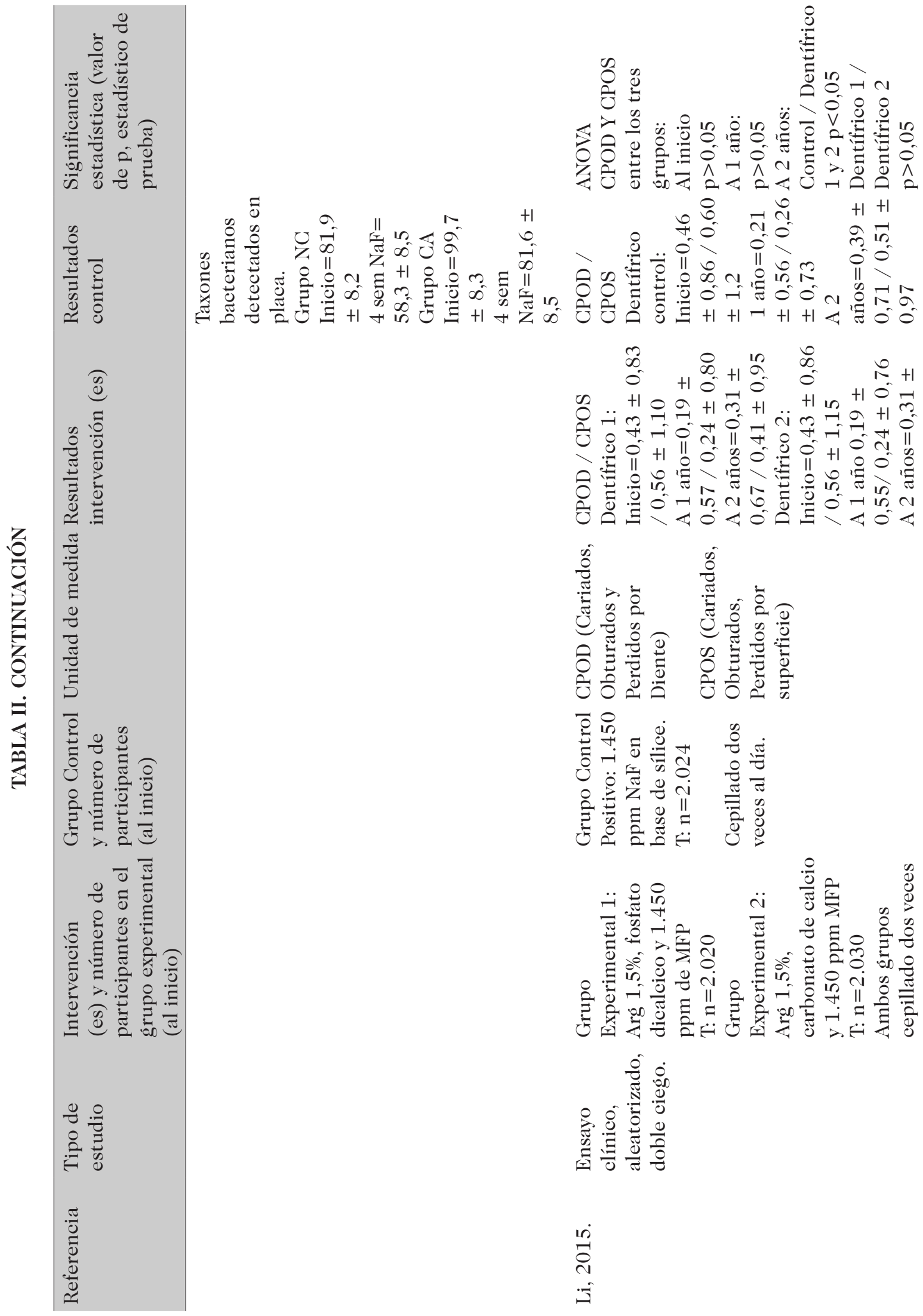

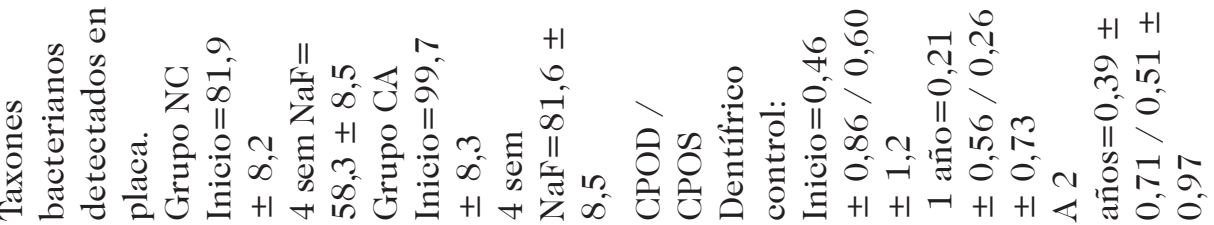

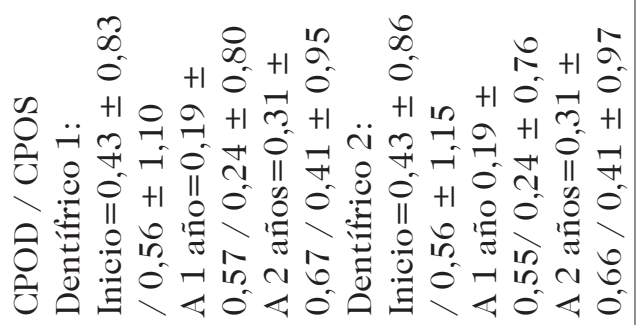

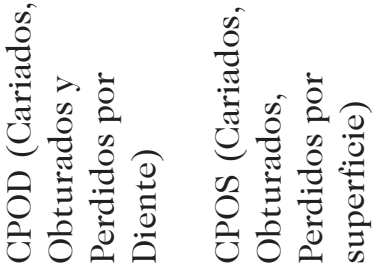

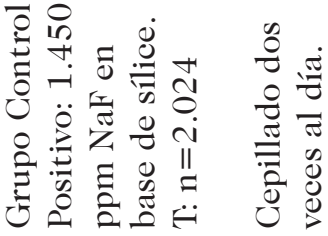

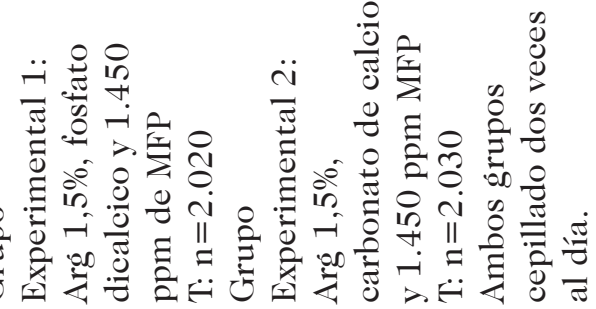

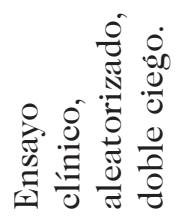

$\frac{10}{8}$ 


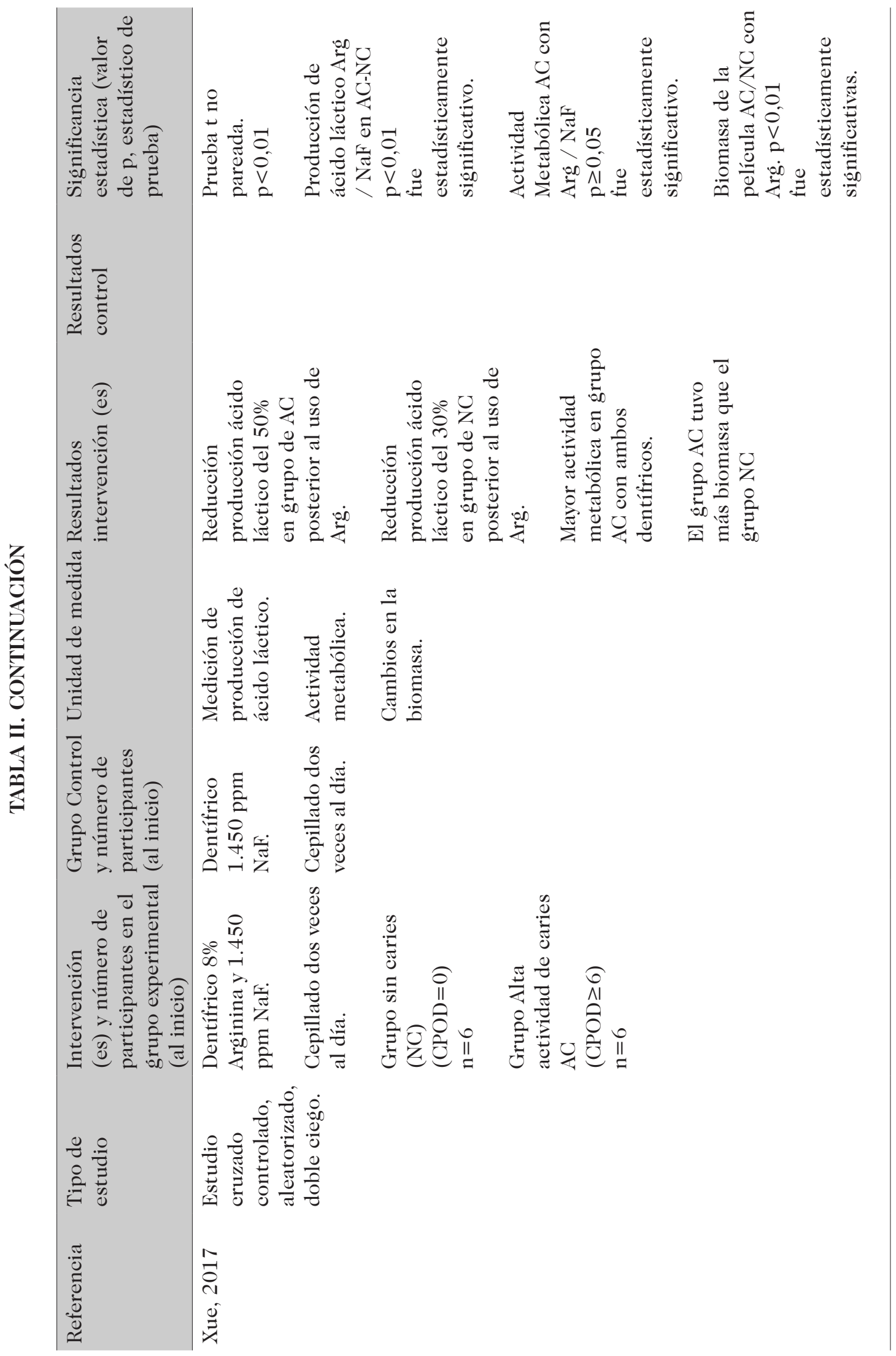

Vol. 62(2): 169 - 188, 2021 


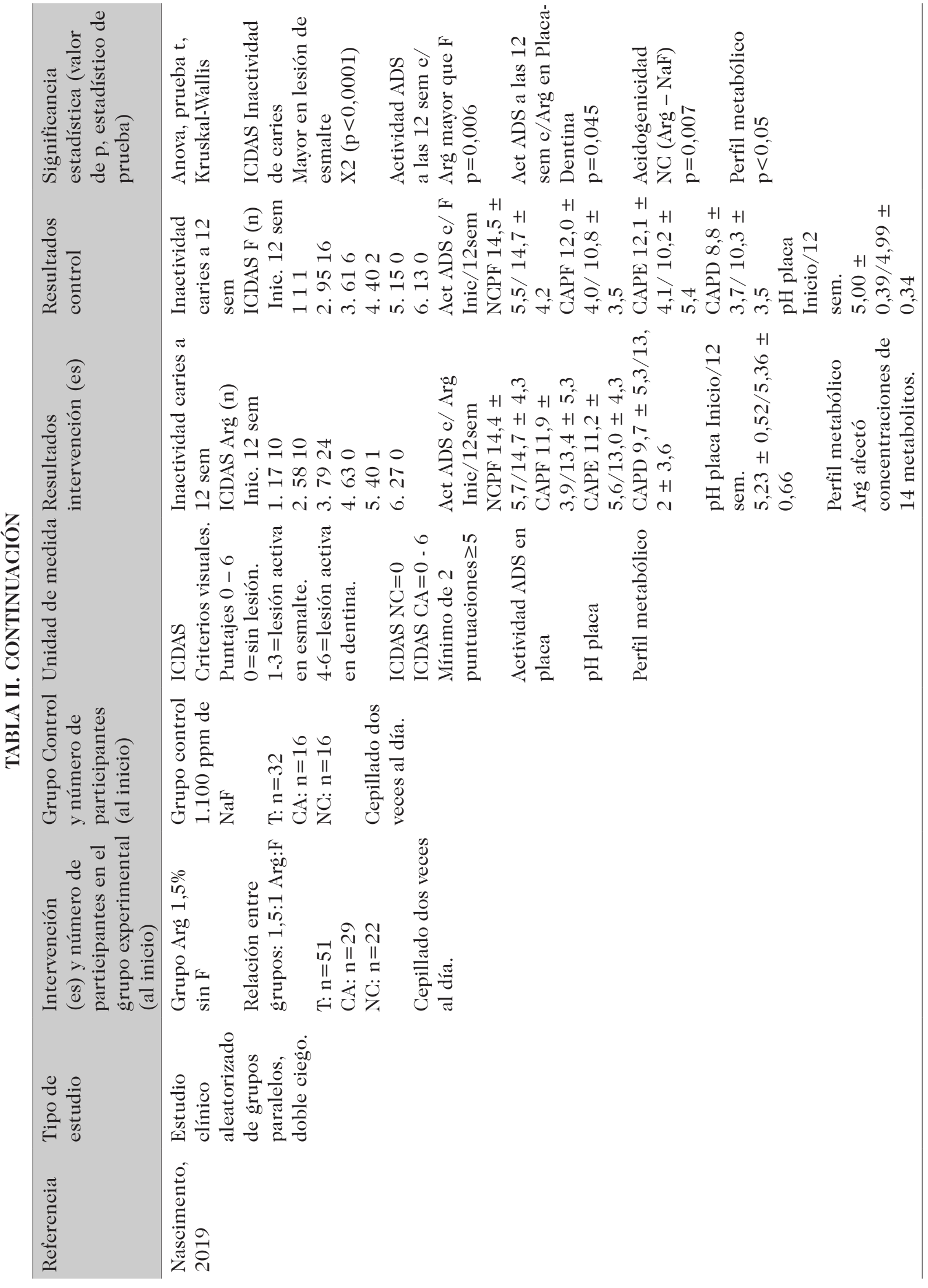




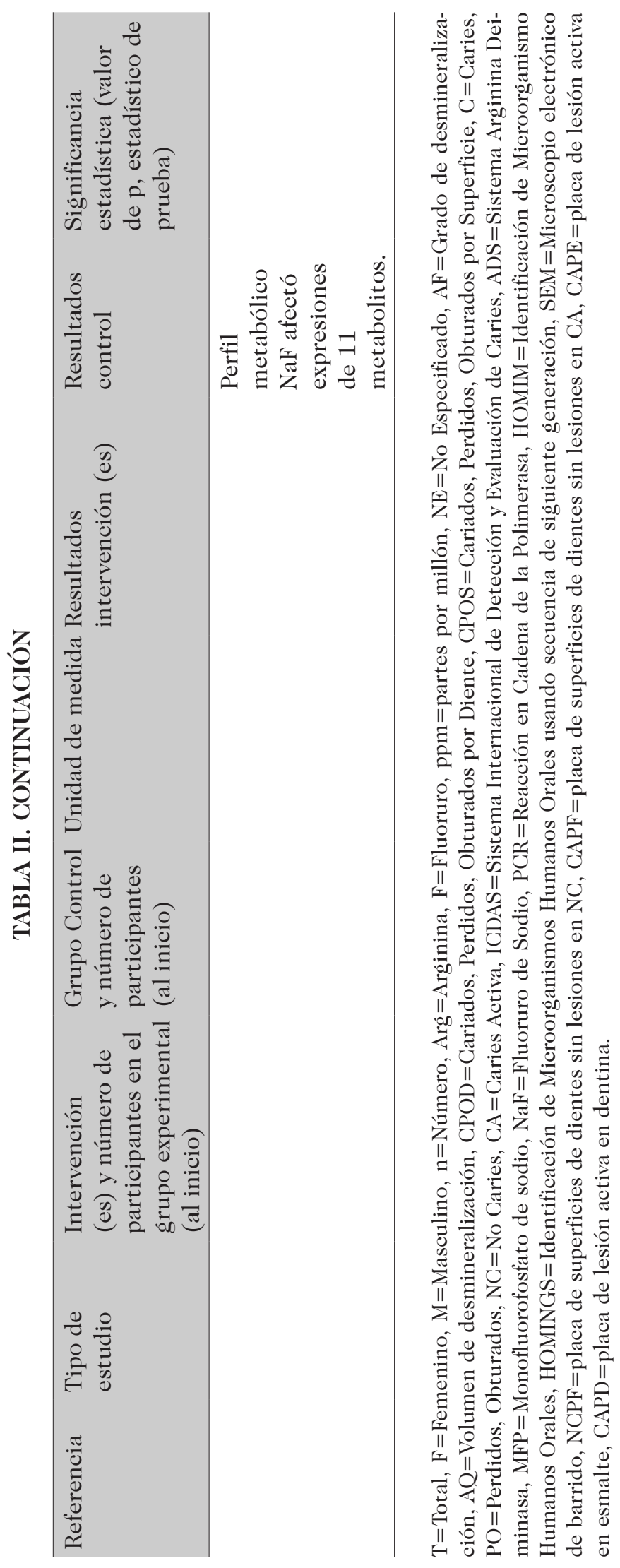

Vol. 62(2): 169 - 188, 2021 


$\begin{array}{llll}\text { Estudio } & \text { Grupo Experimental } & \text { Comparador } & \text { Desenlace } \\ \text { Kraivaphan 2013 } & \text { Dentífrico 1,5\% arg+MFP } & \text { Dentifrico NaF } & \text { CPOD/CPOS } \\ \text { Srisilapanan 2013 } & \text { Dentífrico 1,5\% arg+MFP } & \text { Dentífrico MFP } & \text { Grado de desmineralización/Área y volumen de la lesión } \\ \text { Yin 2013 } & \text { Dentífrico 1,5\% arg+MFP } & \text { Dentífrico NaF } & \text { Grado de desmineralización/Área y volumen de la lesión } \\ \text { Nascimento 2014 } & \text { Dentífrico 1,5\% arg } & \text { Dentífrico NaF } & \text { Act ADS en placa y saliva } \\ \text { Li } 2015 & \text { Dentífrico 1,5\% arg+MFP } & \text { Dentífrico NaF } & \text { CPOD/CPOS } \\ \text { Xue 2017 } & \text { Dentífrico 8\% arg+NaF } & \text { Dentífrico NaF } & \text { Prod ácido láctico/Act.metabólica y en la biomasa } \\ \text { Nascimiento 2019 } & \text { Dentífrico 1,5\% arg } & \text { Dentífrico NaF } & \text { ICDAS/Act ADS en placa/pH placa/Act metabólica }\end{array}$
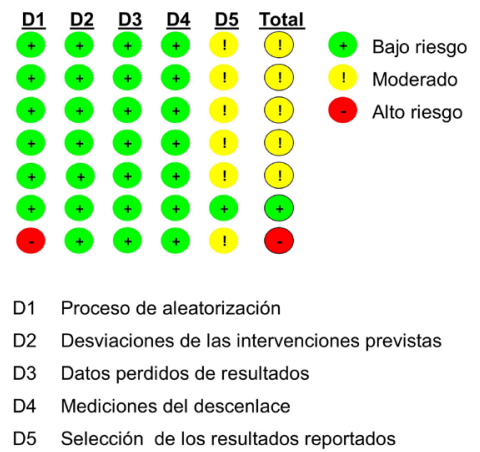

Fig. 2. Evaluación de riesǵo de sesgoo de los estudios incluidos en la revisión sistemática.

va, sobre todo de aquellos participantes con caries activa. Las muestras recolectadas de placa presente en superficies con diferente grado de caries, de acuerdo al Sistema Internacional de Detección y Evaluación de Caries (ICDAS), mostraron que la actividad del SAD de placa presente en lesiones de dentina (ICDAS 4 - 6) fue mayor que aquellas muestras de placa de superficies libre de caries (ICDAS 0). En estos estudios se pudo observar que la cantidad de especies bacterianas presentes en la placa de sujetos con caries activa tratados con arginina, se redujo en comparación con aquellos tratados sólo con flúor. Las especies Veillonella parvula, Fusobacterium nucleatum y Slackia exiǵua redujeron sus porcentajes desde 58-63 y 90\%, respectivamente a 0\%, Prevotella cluster $I V$ se redujo de un $90 \%$ a $63 \%$ posterior al uso de dentífrico con arginina, promoviendo una comunidad bacteriana más saludable en individuos con caries activa.

\section{Área y grado de desmineralización}

El área y grado de desmineralización de lesiones incipientes en esmalte fue evaluado en dos estudios $(23,24)$ durante 6 meses. En el primer estudio se usaron dos dentífricos: uno con arginina al 1,5\% y $1.450 \mathrm{ppm}$ de fluoruro, y otro de control, solamente con 1.450 ppm de fluoruro. Después del tratamiento se observó que la reducción del tamaño de la lesión 3 meses después del uso de dentífri- co con argininina era similar a aquella con un dentífrico con fluoruro convencional durante 6 meses. En el segundo estudio, se evaluó la efectividad de tres dentífricos, uno con arginina al 1,5\% y $1.450 \mathrm{ppm}$ de fluoruro, un control positivo con $1.450 \mathrm{ppm}$ de NaF y un control negativo sin fluoruro. La reducción de la lesión se observó desde los 3 meses, incrementándose aún más a los 6 meses, llegando a un porcentaje de 50,6\% usando arginina contra 34\% con fluoruro. Estos estudios indican que la remineralización de lesiones incipientes se puede obtener dos veces más rápido al usar dentífricos con arginina que con dentífricos convencionales.

Actividad y perfil metabólico de la biopelícula y producción de ácido láctico

Dos estudios evaluaron la actividad y perfil metabólico de la biopelícula y producción de ácido láctico $(3,27)$. Se determinó que la producción de ácido láctico se redujo en grupos de alta actividad cariogénica, incluso más que en aquellos con ausencia de caries, al usarse dentífricos con arginina durante dos semanas. La actividad metabólica y biomasa de la película no sufrieron cambio alguno.

\section{Efectos secundarios}

De los 7 estudios revisados, 3 reportaron la ausencia de cualquier efecto adverso en tejidos blandos o duros de la cavidad oral $(16,23,26)$; el resto, no reportó la existencia de algún efecto adverso $(3,24,25,27)$. 


\section{DISCUSIÓN}

En la presente revisión sistemática se encontró que la adición de arǵinina a dentífricos para la higiene oral proporciona ventajas por encima de los dentífricos sólo con fluoruro usados como controles en los diversos estudios. La reducción en el incremento de los índices CPOD/CPOS, inactividad y remineralización en lesiones cariosas incipientes, incremento en la actividad del $\mathrm{SAD}$, así como la reducción en la producción de ácido láctico, son algunos de los efectos del uso de dentífricos con argininina por periodos determinados. En las intervenciones, el porcentaje de argininina presente en los dentífricos de 6 estudios de esta revisión fue de 1,5\%. En los estudios se utilizó argininina a base de fosfato dicálcico o carbonato de calcio $(16,26)$, arǵinina sin fluoruro $(25,27)$, arginina con $1.450 \mathrm{ppm}$ de fluoruro de sodio (23) y con 1.450 ppm de MFP (24). Sólo un estudio utilizó un porcentaje al 8\% de arginina (3), dicha concentración es utilizada en la mayoría de los estudios donde se evalúa control de sensibilidad dental. Los dentífricos utilizados como control fueron a base de fluoruro, variando entre 1.100 y $1.450 \mathrm{ppm}$; a excepción de un estudio en el que se empleó pasta a base de MFP (24), el resto usó pastas con fluoruro de sodio (NaF).

En los estudios incluidos para realizar el diagnóstico y evaluación de presencia o ausencia de procesos cariosos se utilizaron diferentes métodos. Algunos estudios utilizaron métodos visuales-tácticos para poder determinar el índice CPOD / CPOS $(3,16,25,26)$. Este tipo de métodos tienen limitantes, pues a pesar de ser fácil de aplicar y alcanzar buenos niveles de reproductibilidad (28), en muchos casos sólo registra lesiones de caries en etapa avanzada, pasando por alto aquellas que se puedan encontrar en etapas iniciales. Debido a esto, se desarrolló el índice conocido como ICDAS para mejorar la sensibilidad de la detección de caries en etapas incipientes. Sin embargo, algunos estudios han reportado resultados favorables para encuestas epidemiológicas en las cuales se ha determinado que prolongar un poco más el tiempo requerido para determinar el ICDAS pueda ser una limitante para estudios de campo (29). Este método fue utilizado en un estudio (27) para evaluar los procesos tempranos de caries. En dos estudios $(23,24)$ se utilizó un método de vanguardia para medir las lesiones presentes en esmalte a través del uso de fluorescencia inducida por luz cuantitativa (QLF). Este método permite determinar la existencia de cambios en la remineralización de lesiones en periodos cortos de tiempo (30). Todos los estudios incluidos cumplieron con lineamientos éticos al proporcionar a los participantes pastas dentales y técnicas de prevención que cumplieran con los requerimientos básicos para mantener una adecuada salud bucal, así como dar indicaciones claras sobre la frecuencia del cepillado dental a cada participante (dos veces al día) y en algunos casos incluso, bajo la supervisión de personal de salud dispuesto en las áreas de estudio.

Por otro lado, en revisiones sistemáticas realizadas previamente concluyeron que, a pesar de que la evidencia sugiere que hay un efecto a favor de la intervención, se requieren más estudios que dependan menos de los intereses comerciales para alcanzar una conclusión sólida, lo cual se encuentra en concordancia con lo encontrado en la presente revisión $(6,31)$.

Como es sabido, los patrocinios sobre estudios pueden ocasionar sesgos beneficiando a la industria patrocinadora; generalmente los resultados, efectos secundarios y conclusiones pueden ser favorables si los autores del estudio apoyan el uso de determinados productos (fármacos o dispositivos), incluso si hay ausencia de resultados estadísticamente significativos. Muchas industrias tienen interés en mostrar sus productos en ámbitos científicos, pues de estos resultados dependen muchas tomas de decisiones clínicas y adquisitivas. El patrocinio de la casa comercial que manufactura las pastas dentales con arginina puede introducir sesgos en los

Vol. 62(2): 169 - 188, 2021 
estudios clínicos y generar dudas acerca de la validez de los resultados de los mismos, debido a los potenciales conflictos de interés. Una limitante de esta revisión es probablemente incluir estudios patrocinados, ya que la inclusión de los estudios financiados por la industria puede ser un factor que altere las conclusiones de una revisión sistemática (32). Sin embargó, en la presente revisión no encontramos sesgo importante, a excepción de un estudio incluido. El diseño de los estudios es adecuado, aunque en seis de ellos no se registró el protocolo y se encontró selección de los resultados reportados. Otra potencial fuente de sesgo son las pérdidas de sujetos de los grupos de intervención y control; entre menor número de participantes tenga el estudio, mayor es el impacto de las pérdidas de los participantes. Los dos estudios con menor número de participantes fueron los de Xue y col. y Nascimento y col. $(3,25)$, los cuales tuvieron un porcentaje de pérdida alrededor de 16\%; mientras que los estudios de Kraivaphan y col., Yin y col., Srisilapanan y col., Li y col., Nascimento y col. $(16,23,24,26,27)$, con mayor cantidad de participantes, mostraron porcentajes de pérdida que oscilaron entre 1,78 y $9,4 \%$. Estos aspectos relacionados al sesgo que se han discutido, generan ciertas dudas acerca de la confiabilidad de los resultados.

Por otra parte, en lo que concierne al efecto anticaries de la argínina, aún quedan diversos puntos a clarificarse tales como la eficacia de esta pasta para detener el proceso carioso cuando ha alcanzado a la dentina o si tiene un efecto similar en niños y en adultos, ya que la dieta e higiene entre los diferentes grupos etarios pueden ser factores que intervengan en los resultados. Asimismo, no hay evidencia del efecto anticaries de los dentífricos con argininina en dientes temporales.

Considerando los artículos analizados en la presente revisión, se puede concluir que los dentífricos que combinan arginina con bases de fosfato dicálcico o $\mathrm{NaF}$ poseen un efecto anticariogénico superior que aquellos dentífricos convencionales, disminuyendo los procesos cariogénicos, inactivando y remine- ralizando lesiones incipientes dos veces más rápido, aumentando la actividad $\mathrm{SAD}$ a través de microorganismos productores de amoníaco, reduciendo la producción de ácido láctico todo lo cual genera un beneficio a la salud y bienestar oral. Se recomienda que, en el futuro, se realicen ensayos clínicos aleatorizados independientes con un registro de protocolo, rigurosa descripción metodológica, en los cuales se evalué la incidencia de caries, con un seguimiento mayor a un año, estratificando el empleo en dientes temporales y permanentes para contar con evidencia robusta acerca del efecto anticariogénico de las pastas dentales con arginina.

\section{AGRADECIMIENTOS}

Agradecemos al programa Cátedras Conacyt, a la Facultad de Odontología, así como a la División de Posgrado de esta Facultad, pertenecientes a la Universidad Autónoma "Benito Juárez" de Oaxaca, así como a los Cuerpos Académicos "Investigación en Salud" UABJO-CA-63.

\section{REFERENCIAS}

1. Mejia C, Alanís J, Argueta L, Legorreta A. Academic stress as a risk factor for dental caries. Int Dent J 2012; 62: 127-131.

2. Berto A, Lauener A, Saads T, Lussi A, Eick S. In vitro effects of arginine containing toothpastes on cariogenic biofilms. Oral Health Prev Dent 2019; 17: 375-383.

3. Xue Y, Lu Q, Tian Y, Zhou X, Cheng L, Ren B. Effect of toothpaste containing arginine on dental plaque-A randomized controlled in situ study. J Dent 2017; 67: 88-93.

4. Marsh PD. Dental plaque: biological significance of a biofilm and community life-style. J Clin Periodontol 2005; 32: 7-15.

5. Featherstone JDB. Dental caries: a dynamic disease process. Aust Dent J 2008; 53: 286-291.

6. Ástvaldsdóttir A, Naimi-Akbar A, Davidson T, Brolund A, Lintamo L, Attergiren A, Tranæus S, Östlund P. Arǵinine and caries prevention: A systematic review. Caries Res 2016; 50: 383-393. 
7. Argueta L, Torres N, Garcia R, Vilchis A, Martínez O, Acosta L, Arenas M. Hydrothermal synthesis of pyrrhotite $\left(\mathrm{Fe}_{\mathrm{x}-1} \mathrm{~S}\right)$ nanoplates and their antibacterial, cytotoxic activity study. Prog. Nat. Sci. 2018; 28: 447-455.

8. Argueta L, Martínez O, Santos J, García R, Acosta L, De la fuente J, Arenas M. Nanomateriales made of non-toxic metallic sulfides: a systematic review of their potential biomedical applications. Mater Sci Eng C Mater Biol Appl 2017; 76: 1305-1315.

9. Argueta L, Arenas M, Díaz A, García S, García R. Propiedades antimicrobianas y citotóxicas de un adhesivo de uso ortodóncico adicionado con nanoparticulas de plata. Mundo Nano 2019; 12: 1e-13e.

10. Argueta L, Morales R, Scougall R, Olea O. Synthesis, characterization and antibacterial activity of copper, nickel and bimetallic Cu-Ni nanoparticles for potential use in dental materials. Prog. Nat. Sci. 2014; 24: 321-328.

11. Torres R, Torres N, Moreno A, Garcia R, Argueta L. Anti-inflammatory and antibacterial activity of the Chitosan/Chlorhexidine gel commercial preparation for postexodontia treatment: an in vitro study. Eur J Dent 2020; 14: 397-403.

12. Chakraborty B, Burne A. Effects of arginine on Streptococcus mutans growth, virulence gene expression, and stress tolerance. Appl Environ Microbiology 2017; 83: 1-13.

13. Gurenlian JR. The role of dental plaque biofilm in oral health. J Dent Hyg 2007;

81: 1-11.

14. Souza R, Cury JA, Tenuta A, Zhang P, Mateo R, Cummins D, Ellwod P. Comparing the efficacy of a dentifrice containing 1,5 arǵinine and $1450 \mathrm{ppm}$ fluoride to a dentifrice containing 1450 ppm fluoride alone in the management of primary root caries. J Dent 2010; 38: 34-40.

15. Reyes É, Martín J, Yevenes I, Neira M, Palma P, Gordan V, Moncada G. Actividad y efectos de ureasa y arǵinina deiminasa en saliva y biopelícula oral humana. Rev Fac Odontol Univ Antioq 2012; 23: 343-352.

16. Kraivaphan $P$, Amornchat $C$, Triratana $T$, Mateo R, Ellwood P, Cummins D, DeVizio W, Zhang $\mathbf{P}$. Two-year caries clinical study of the efficacy of novel dentifrices containing $1,5 \%$ arginine, an insoluble calcium com- pound and 1450 ppm fluoride. Caries Res 2013; 47: 582-590.

17. Cheng $X, X u P$, Zhou $X$, Deng $M$, Cheng $L$, Li M, Li Y, Xu X. Arǵinine promotes fluoride uptake into artificial carious lesions in vitro. Aust Dent J 2015; 60: 104-111.

18. Fernández M, Martinez A, Arriarán E, Gutiérrez D, Toriz H, Lifshitz A. Uso de los MeSH. Inv Ed Med 2016; 5: 220-229.

19. Urrútia G, Bonfill X. Declaración PRISMA: una propuesta para mejorar la publicación de revisiones sistemáticas y metanálisis. Med Clin (Bare) 2010; 135: 507-511.

20. Moher D, Liberati A, Tetzlaff J, Altman G. The PRISMA group. Preferred reporting tems for systematic review and meta-analyses: The PRISMA statement. PLoS Med. 2009; 6: e1000097. doi: 10.1371/journal. pmed1000097.

21. Higgins JPT, Savovi' c J, Page MJ, Elbers RG, Sterne JAC. Chapter 8: Assessing risk of bias in a randomized trial. In: Higg gins JPT, Thomas J, Chandler J, Cumpston M, Li T, Paǵe MJ, Welch VA (editors). Cochrane Handbook for Systematic Reviews of Interventions version 6.2 (updated February 2021). Cochrane, 2021. Available from http://www. training.cochrane.org/handbook

22. Sterne JAC, Savovi'e J, Page MJ, Elbers RG, Blencowe NS, Boutron I, Cates CJ, Cheng HY, Corbett MS, Eldridge SM, Emberson JR, Hernán MA, Hopewell S, Hróbjsrtsson A, Junqueira DR, Jüni P, Kirkham JJ, Lasserson T, Li T, McAleenan A, Reeves BC, Shepperd S, Shrier I, Stewart LA, Tilling K, White IR, Whiting PF, Higgins JPT. RoB 2 a revised tool for assessing risk of bias in randomized trials. BMJ. 2019; 366: I4898.

23. Yin W, Hu Y, Li X, Fan X, Zhang P, Pretty A, Mateo R, Cummins D, Ellwood P. The anti-caries efficacy of a dentifrice containing $1,5 \%$ arginine and $1450 \mathrm{ppm}$ fluoride as sodium monofluorophosphate assessed using Quantitative Light-induced Fluorescence (QLF). J Dent 2013: s22-s28.

24. Srisilapanan P, Korwanich N, Yin W, Chuensuwonkul C, Mateo R, Zhang P, Cummins D, Ellwood P. Comparison of the efficacy of a dentifrice containing 1,5\% arginine and $1450 \mathrm{ppm}$ fluoride to a dentifrice containing 1450 ppm fluoride alone in

Vol. 62(2): 169 - 188, 2021 
the management of early coronal caries as assessed using Quantitative Light-induced Fluorescence. J Dent 2013: s29-s34.

25. Nascimento N, Browngardt C, Xiaohui X, Klepac-Ceraj V, Paster J, Burne A. The effect of arginine on oral biofilm communities. Mol Oral Microbiol 2014; 29: 45-54.

26. Li X, Zhong Y, Jiang X, Hu D, Mateo R, Morrison M, Zhang Y. Randomized clinical trial of the efficacy of dentifrices containing 1,5\% arginine, an insoluble calcium compound and $1450 \mathrm{ppm}$ fluoride over two years. J Clin Dent 2015; 26: 7-12.

27. Nascimento $M$, Alvarez $J$, Huang $X$, Browngardt C, Jenkins R, Sinhoreti C, Ribeiro D, Dilbone A, Richards P, Garrett J, Burne A. Metabolic profile of supragingival plaque exposed to arginine and fluoride. J Dent Res 2019; 98: 1245-1252.

28. Campus G, Coceo F, Ottolengihi L, Cagetti G. Comparison of ICDAS, CAST, Nyvad's criteria, and WHO-DMFT for caries detection in a sample of Italian schoolchildren. Int J Environ Res Public Health 2019; 16: 4120-4134.
29. Taqi M, Razak A, AB-Murat N. Comparing dental caries status using Modified International Caries Detection and Assessment System (ICDAS) and World Health Organization (WHO) indices among school children of Bhakkar, Pakistan. J Pak Med Assoc 2019; 69: 950-954.

30. Pretty A, Ellwood P. The caries continuum: opportunities to detect, treat and monitor the re-mineralization of early caries lesions. J Dent 2013: s12-s21.

31. Li J, Huang Z, Mei L, Li G, Li H. Anti-caries effect of arginine-containing formulations in vivo: A systematic review and metaanalysis. Caries Res 2015; 49: 606-617.

32. Lundh A, Lexchin J, Mintzes B, Schroll B, Bero L. Industry sponsorship and research outcome. Cochrane Database Sys Rev 2017; 2: MR000033. 